\title{
Wnt signaling meets internal dissent
}

\author{
Elizabeth A. Grove ${ }^{1}$ \\ Department of Neurobiology, University of Chicago, Chicago, Illinois 60637, USA
}

In canonical Wnt signaling, $\beta$-catenin translocates to the cell nucleus, interacting with Tcf/Lef factors to activate transcription of Wnt target genes. In this issue of Genes \& Development, Vacik and colleagues (pp. 1783-1795) report that a highly conserved sequence in intron 5 of $T c f 712$ conceals an internal promoter region that, when activated by Vax2, drives transcription of truncated $T c f 712$ mRNAs. The encoded Tcf712 protein binds to DNA, but not $\beta$-catenin, and therefore acts as a dominant-negative Wnt antagonist.

Canonical or $\beta$-catenin-mediated Wnt signaling is strictly regulated, as befits a signaling pathway used repeatedly in the course of development and whose dysregulation is involved in several cancers (Moon et al. 2002). Inhibitory mechanisms come into play when the Wnt ligand is released, and continue, as Vacik et al. (2011) demonstrate, to the final stage of canonical Wnt signaling, at which nuclear $\beta$-catenin binds to Tcf/Lef transcription factors, activating transcription of downstream Wnt target genes.

\section{Regulation of canonical Wnt signaling}

When a cell signals to another by releasing the Wnt ligand, the ligand binds to Frizzled receptors on the recipient cell (Wodarz and Nusse 1998) as well as the Wnt coreceptors LDL receptor-related proteins 5 and 6 (LRP5/6) (Tamai et al. 2000) to form a trimeric complex required for signaling (Schweizer and Varmus 2003). The Wnt ligand must first, however, avoid a variety of alternative binding partners, including the secreted Frizzled-related proteins (sFrps) (Rattner et al. 1997), which contain the Frizzled cysteine-rich Wntbinding domain but no transmembrane domain, and Wnt inhibitory factors (Wifs) (Hsieh et al. 1999). By sequestering the Wnt ligand, these inhibitors restrict the range and strength of Wnt signaling. Meanwhile, members of a third family of secreted proteins, the Dickkopf (Dkk) family of Wnt modulators (Niehrs 2006), can interact with LRP5/6 coreceptors and inhibit Wnt signaling by disrupting LRP5/6 binding to the Wnt/Frizzled complex (Brott and Sokol 2002). Once the Wnt ligand has successfully bound to its Frizzled receptors and LRP5/6 coreceptors, the Dishevelled (Dvl)

[Keywords: Vax genes; Sonic hedgehog; canonical Wnt signaling; brain development]

${ }^{1}$ Correspondence.

E-mail egrove@bsd.uchicago.edu.

Article is online at http://www.genesdev.org/cgi/doi/10.1101/gad.17594311. protein is activated. Dvl inhibits the activity of a protein complex that includes glycogen synthase kinase $3 \beta$ (GSK3 $\beta$ ) and adenomatosis polyposis coli (APC), an important tumor suppressor gene in colon cancer. This protein complex is the principal block to nuclear $\beta$-catenin signaling. In the absence of a Wnt signal, GSK3 $\beta$ phosphorylates $\beta$-catenin, which results in $\beta$-catenin degradation through the ubiquitin pathway (Fig. 1A; Aberle et al. 1997). After Dvl inhibits the activity of the protein complex, $\beta$-catenin is free to enter the cell nucleus, where it complexes with transcription factors of the T-cell factor and lymphoid enhancer factor (Tcf/Lef) family, displacing corepressors such as Groucho/ TLE repressors (Daniels and Weis 2005) and histone deacetylases (HDACs) (Hurlstone and Clevers 2002), and promoting $\beta$-catenin/Tcf/Lef interactions with coactivators to drive expression of Wnt target genes (Fig. 1B).

\section{A novel form of inhibition of a Tcf/Lef transcription factor}

Vacik et al. (2011) have discovered an intriguing new way in which canonical Wnt signaling can be controlled. A member of the Tcf/Lef family, Tcf4, now called Tcf712, normally binds to $\beta$-catenin to mediate Wnt signaling at several sites in the body and brain. The present study describes an internal promoter region within intron 5 of the Tcf7l2 gene that drives transcription of truncated Tcf7l2 mRNAs. Vacik et al. (2011) demonstrate that these truncated mRNAs are endogenously expressed in mice and Xenopus, and at least two mRNAs generate substantial truncated Tcf712 protein in vivo in mice. The truncated Tcf712 mRNAs contain only exons 6 and beyond, critically lacking exon 1, which contains a sequence encoding the $\beta$-catenin-binding site of Tcf712. Truncated Tcf712 protein thus cannot bind to $\beta$-catenin, but maintains an HMG DNA-binding domain, as well as domains that should ensure nuclear localization and interaction with the Groucho/ TLE corepressors. Consequently, the truncated protein acts in the nucleus as dominant-negative Tcf712 (dnTcf712). DnTcf712 competes with full-length Tcf712 in binding to a common DNA-binding site, but by failing to bind $\beta$-catenin, dnTcf 712 remains as a transcriptional repressor, blocking the transcription of Wnt target genes (Fig. 1C).

The role of Vax genes in generating dominant-negative Tcf712 proteins

A long-standing program of research in the Lemke laboratory concerns the patterning of the vertebrate eye (Kim 

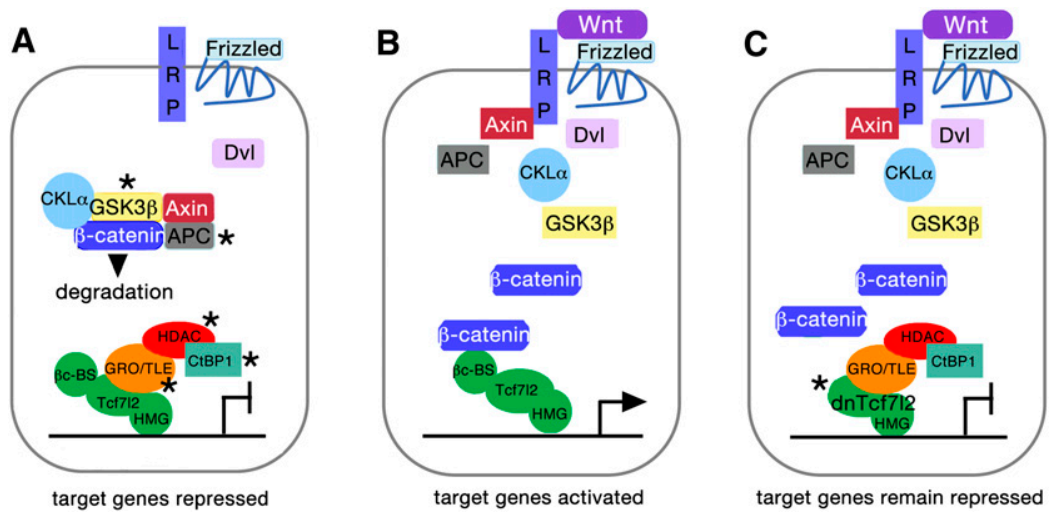

target genes remain repressed

Figure 1. $(A-C)$ Schematics of Wnt signaling components in the absence of a Wnt signal $(A)$, the presence of a Wnt signal $(B)$, and the presence of a Wnt signal blocked by the displacement of Tcf712 by dnTcf712 (C). (A) Without a Wnt signal, $\beta$-catenin is phosphorylated by a protein complex surrounding GSK3 $\beta$ and sent for ubiquitination. In the nucleus of the cell, Tcf712 associates with the Groucho-TLE corepressors, as well as other repressors (HDAC and CtBP1). Transcription of Wnt target genes is repressed. Asterisks indicate components of the Wnt signaling pathway that Vacik et al. (2011) found are up-regulated by Vax 2 (see also $C$ ). $(B)$ The Wnt ligand binds to its Frizzled receptors and LRP coreceptors. Dvl breaks up the GSK3 $\beta$-centered protein complex, releasing $\beta$-catenin, which translocates to the nucleus, displaces corepressors, and attaches to the $\beta$-catenin-binding site $(\beta \mathrm{c}$-BS) on Tcf712. Target Wnt genes are expressed. $(C)$ DnTcfl72 has displaced Tcf712 in the nucleus. Because dnTcfl72 lacks a $\beta$-catenin-binding site, it remains a transcriptional repressor even in the presence of a Wnt signal and the subsequent availability of $\beta$-catenin. The cell has, in effect, become "blind" to the Wnt signal (see Vacik et al. 2011).

and Lemke 2006). Previous studies have shown that the dorsal-ventral $(\mathrm{D} / \mathrm{V})$ axis of the retina is established and maintained in part by a competition between Sonic hedgehog (Shh) signaling ventrally and Wnt signaling dorsally, in combination with signaling by FGFs, bone morphogenetic proteins (BMPs), and retinoids (Huh et al. 1999; Halilagic et al. 2007; Veien et al. 2008; Zhao et al. 2010). Shh induces the transcription factor Vax2 (Kim and Lemke 2006), previously found to be expressed in the ventral retina and to regulate D/V eye patterning (Barbieri et al. 1999; Kim and Lemke 2006). A specific search for genes downstream from Vax2 led to the identification of Vax2-binding sites in the $\sim 700$-base-pair (bp)-long sequence of intron 5 of the Tcf7l2 gene, which Vacik et al. (2011) subsequently found to contain an internal promoter region for dnTcf712. Four truncated mRNAs initiating in the fifth intron of the Tcf7l2 gene were identified by 5 ' RACE from exon 8 ; the alternative first exons of these truncated Tcf712 isoforms were designated $1 \mathrm{~b}, 1 \mathrm{c}, 1 \mathrm{~d}$, and $1 \mathrm{e}$. Of these, mRNA for $1 \mathrm{~b}$ and $1 \mathrm{c}$ was most strongly expressed in the mouse embryo, beginning at about embryonic day 9 (E9). Notably, these mRNAs were expressed in the head, particularly in the diencephalon of the brain and in the Vax2-expressing retina and optic stalk, but were essentially absent from the embryo body. Confirming that expression of $d n T c f 712$ mRNAs depends on Vax2, at least in the ventral retina, $1 \mathrm{~b}$ dnTcf712 mRNA is normally expressed throughout the retina, but expression is specifically lost in the ventral neural retina of Vax2-null mutants. Meanwhile, as would be expected, expression of full-length Tcf712 remains the same in the Vax2 mutants. Further experiments designed to clarify Vax2 regulatory activity indicate that Vax2 is a direct transcriptional activator of $d n T c f 712$. These findings revealed an important mechanism by which Shh can antagonize the dorsalizing activity of Wnt signaling in the retina.

\section{Vax2 activation of a suite of Wnt antagonists}

Intriguing additional findings suggest that Vax2 not only up-regulates $d n T c f 712$, but also a variety of genes encoding proteins with a role in Wnt signaling inhibition: Tle1, Hdac2, Ctbp1, Apc, and Gsk3ß (see Fig. 1A). Tle1 is a Groucho-associated TLE corepressor, Hdac2 and C-terminal binding protein 1 (Ctbp1) serve as epigenetic corepressors, and APC and Gsk3b are both components of the protein complex that leads to $\beta$-catenin degradation in the absence of a Wnt signal. Tle1, Hdac2, Ctbp1, Apc, and Gsk $3 \beta$ expression is coextensive in the ventral retina with that of $d n T c f 712$ and Vax2 and is lost in the ventral but not dorsal retina of $\operatorname{Vax}^{-/-}$mice, indicating a dependency on Vax2 regulation. Although Vacik et al. (2011) did not find Vax2 binding in known regulatory regions of the Tle1, Hdac2, Ctbp1, Apc, and Gsk3 $\beta$ genes, the introns of these genes contained putative Vax2-binding sites. Clearly, how Shh-induced Vax2 regulates expression of other Wnt antagonist genes warrants further investigation.

\section{Reduced dnTcf712 leads to a phenotype characteristic of decreased Wnt inhibition}

Emphasizing the importance of Wnt signaling inhibition, and introducing a phenotype that Vacik et al. (2011) recapitulate, the investigators who initially described Dkk1 in Xenopus (Glinka et al. 1998) additionally demonstrated that Dkk1 was necessary and sufficient for Xenopus head induction. Mice lacking Dkk1 also fail to develop rostral structures of the head and brain (Mukhopadhyay et al. 2001).

Vacik et al. (2011) assessed the effects of knocking down dnTcf712 function in Xenopus, first confirming that an endogenous $X d n T c f 712$ exists and is expressed just after the completion of gastrulation. As in mice, $X d n T c f 712$ is expressed strongly and selectively in the head and brain. Morpholino antisense oligonucleotides were designed to knock down XdnTcf712 without affecting full-length XTcf712. The selected morpholinos blocked splicing of alternative exon Ib to exon 6 (not a splicing event required to generate full-length XTcf712) or blocked translation from an ATG start site in the alternative exon $1 \mathrm{~b}$ in Xenopus. Morphants showed a range of effects on head 
development, from a small head and eyes to complete loss of both. Although a full phenotypic analysis of the neural structures that remain in the less affected morphants remains to be done, it appears that a reduction of dnTcf7l2 has severe effects on head and rostral brain formation comparable with a deficiency in Dkk1 in Xenopus and mice (Glinka et al. 1998; Mukhopadhyay et al. 2001).

\section{Other morphogens and transcription factors may regulate $\operatorname{dnTcf} 712$ production}

Production of dnTcf712 and the consequent inhibition of full-length Tcf712 activity do not always require transcriptional activation by Vax proteins or even Shh induction of specific transcription factors. Mice that lack both Vax1 and Vax2 function show a transformation of the optic nerve into retina, a dorsalization of the eye (Mui et al. 2005) and its retinocollicular projections (Mui et al. 2002). Importantly, however, mice that lack both Vax1 and Vax2 do not show the dramatic loss of rostral brain and head that follows knockdown of XdnTcf712 in Xenopus; that is, there are major sites of dnTcf712 function outside the eye that do not express Vax1 or Vax2.

The nucleotide sequence in intron 5 of Tcf712, containing Vax2-binding sites and an internal promoter for truncated $T c f 712$, is astonishingly highly conserved across vertebrates, showing $>85 \%$ identity between humans and puffer fish (Vacik et al. 2011). Vacik et al. (2011) found just over 20 other human noncoding sequences of comparable length that showed as high a sequence conservation; of these, only three sequences were longer. Against the background of the high conservation of Wnt signaling components in general, the hyperconservation of the region of Tcf7l2 intron 5 suggests a role of fundamental biological importance. Unsurprisingly, transcription factors other than Vax proteins, regulated by other morphogens, are likely to activate or repress transcription of $d n T c f 712$. Future studies should discover what these are, and may uncover additional biological functions for this highly conserved stretch of noncoding DNA.

\section{Biological roles for $\operatorname{dnTcf} 712$}

Determining how dnTcf712 influences a variety of events in development or disease will be a future challenge. Initial guidance comes from our current knowledge of the expression patterns of full-length Tcf712 and the functions of Tcf712 in the embryo and adult. Tcf712 activity influences organogenesis of the intestine (Faro et al. 2009), homeostasis of skin epithelium (Nguyen et al. 2009), myogenesis (Mathew et al. 2011), and pituitary development (Brinkmeier et al. 2003). In the CNS, Tcf7l2 regulates the differentiation of a major population of glial cells, oligodendrocytes (Ye et al. 2009). In an interesting reappearance of mutual antagonism between Wnt and Shh signaling, the stabilization and nuclear translocation of $\beta$-catenin negatively regulates oligodendrocyte development by repressing Shh-induced Olig2 expression (Ye et al. 2009). Tcf7ll appears to mediate this negative regulation in part: Mice deficient in Tcf7l2 have defects in oligoden- drocyte maturation, whereas an artificially generated dominant-repressive form of Tcf7l1 promotes precocious oligodendrocyte specification in the chick (Ye et al. 2009). As noted by Vacik et al. (2011), Tcf712 is also strongly expressed in the developing and adult thalamus (Shimogori et al. 2004; Lee et al. 2009), where its functions are currently unknown. With respect to disease, Tcf7l2 has been implicated in the survival of insulin-producing pancreatic $\beta$ cells, and variants of the human TCF7L2 gene have been associated with type 2 diabetes mellitus (Shu et al. 2009). Perhaps most striking, inappropriate activation of a Tcf712 target gene program promotes tumorigenesis in colorectal cancer (Hatzis et al. 2008). In each of these developmental and disease contexts, we now need to discover the role of dnTcfl2. Does it play an important role in suppressing Wnt activity during oligodendrocyte development? Do mutations in $\operatorname{dnTcf712}$ contribute to colorectal cancer or to type 2 diabetes?

A standard way to investigate the functions of a new gene is to knock it out in mice, either constitutively or conditionally. Such an approach has particular difficulties in this case. An existing Tcf712-null mouse engineered to lack a functional HMG domain (Korinek et al. 1998) presumably shows loss of function of both full-length Tcf712 and dnTcf712, given that both proteins use the same HMG DNA-binding site. A mouse that lacks the $\beta$-tubulinbinding site in Tcf7l2 has also been generated (Angus-Hill et al. 2011), but although this might mimic overexpression of dnTcf7l in some ways, exactly which ways might be difficult to tease out. A mouse genetically engineered to produce functional full-length Tcf712, but not dnTcf712, would be ideal for working out the functions of dnTcf7l2 in the body and brain, although making such a mouse offers knotty problems of vector design.

In summary, Vacik et al. (2011) found that Shh-induced Vax2 promotes the generation of a $\operatorname{dnTcf} 712$ protein that blocks canonical Wnt signaling, providing significant insight into the mechanisms of patterning in the eye. Still more significant, they discovered that dnTcf712 mRNA is generated from an alternative first exon that lies hidden inside the fifth intron of the gene encoding Tcf7l2 itself. This observation raises the question of how often either the Wnt or other signaling pathways are faced with this particular type of internal dissent. Another interesting feature of Wnt inhibition mediated by dnTcf7l2 is that it comes at the very end of the Wnt signaling pathway, emphasizing again that Wnt signaling must be kept under very tight control. A final major finding of the current study is that the 700-bp sequence containing Vax2-binding sites and a promoter region for $d n T c f 7$ is extraordinarily highly conserved. This degree of conservation suggests that the 700-bp sequence may have further biological functions that are not yet disclosed.

\section{Acknowledgments}

This work was supported by NIH R37 MH059962 (to E.A.G.).

\section{References}

Aberle H, Bauer A, Stappert J, Kispert A, Kemler R. 1997. $\beta$-Catenin is a target for the ubiquitin-proteasome pathway. $E M B O$ J 16: 3797-3804. 
Angus-Hill ML, Elbert KM, Hidalgo J, Capecchi MR. 2011. T-cell factor 4 functions as a tumor suppressor whose disruption modulates colon cell proliferation and tumorigenesis. Proc Natl Acad Sci 108: 4914-4919.

Barbieri AM, Lupo G, Bulfone A, Andreazzoli M, Mariani M, Fougerousse F, Consalez GG, Borsani G, Beckmann JS, Barsacchi G, et al. 1999. A homeobox gene, vax2, controls the patterning of the eye dorsoventral axis. Proc Natl Acad Sci 96: 10729-10734.

Brinkmeier ML, Potok MA, Cha KB, Gridley T, Stifani S, Meeldijk J, Clevers H, Camper SA. 2003. TCF and Grouchorelated genes influence pituitary growth and development. Mol Endocrinol 17: 2152-2161.

Brott BK, Sokol SY. 2002. Regulation of Wnt/LRP signaling by distinct domains of Dickkopf proteins. Mol Cell Biol 22: 6100-6110.

Daniels DL, Weis WI. 2005. $\beta$-Catenin directly displaces Groucho/ TLE repressors from Tcf/Lef in Wnt-mediated transcription activation. Nat Struct Mol Biol 12: 364-371.

Faro A, Boj SF, Ambrosio R, van den Broek O, Korving J, Clevers H. 2009. T-cell factor 4 (tcf712) is the main effector of Wnt signaling during zebrafish intestine organogenesis. Zebrafish 6: $59-68$.

Glinka A, Wu W, Delius H, Monaghan AP, Blumenstock C, Niehrs C. 1998. Dickkopf-1 is a member of a new family of secreted proteins and functions in head induction. Nature 391: 357-362.

Halilagic A, Ribes V, Ghyselinck NB, Zile MH, Dolle P, Studer M. 2007. Retinoids control anterior and dorsal properties in the developing forebrain. Dev Biol 303: 362-375.

Hatzis P, van der Flier LG, van Driel MA, Guryev V, Nielsen F, Denissov S, Nijman IJ, Koster J, Santo EE, Welboren W, et al. 2008. Genome-wide pattern of TCF7L2/TCF4 chromatin occupancy in colorectal cancer cells. Mol Cell Biol 28: 2732-2744.

Hsieh JC, Kodjabachian L, Rebbert ML, Rattner A, Smallwood PM, Samos CH, Nusse R, Dawid IB, Nathans J. 1999. A new secreted protein that binds to Wnt proteins and inhibits their activities. Nature 398: 431-436.

Huh S, Hatini V, Marcus RC, Li SC, Lai E. 1999. Dorsal-ventral patterning defects in the eye of BF-1-deficient mice associated with a restricted loss of shh expression. Dev Biol 211: 53-63.

Hurlstone A, Clevers H. 2002. T-cell factors: turn-ons and turnoffs. EMBO J 21: 2303-2311.

Kim JW, Lemke G. 2006. Hedgehog-regulated localization of Vax2 controls eye development. Genes Dev 20: 2833-2847.

Korinek V, Barker N, Moerer P, van Donselaar E, Huls G, Peters PJ, Clevers H. 1998. Depletion of epithelial stem-cell compartments in the small intestine of mice lacking Tcf-4. Nat Genet 19: 379-383.

Lee S, Lee CE, Elias CF, Elmquist JK. 2009. Expression of the diabetes-associated gene TCF7L2 in adult mouse brain. I Comp Neurol 517: 925-939.

Mathew SJ, Hansen JM, Merrell AJ, Murphy MM, Lawson JA, Hutcheson DA, Hansen MS, Angus-Hill M, Kardon G. 2011. Connective tissue fibroblasts and Tcf4 regulate myogenesis. Development 138: 371-384.

Moon RT, Bowerman B, Boutros M, Perrimon N. 2002. The promise and perils of Wnt signaling through $\beta$-catenin. Science 296: 1644-1646.

Mui SH, Hindges R, O'Leary DD, Lemke G, Bertuzzi S. 2002. The homeodomain protein Vax2 patterns the dorsoventral and nasotemporal axes of the eye. Development 129: 797-804.

Mui SH, Kim JW, Lemke G, Bertuzzi S. 2005. Vax genes ventralize the embryonic eye. Genes Dev 19: 1249-1259.
Mukhopadhyay M, Shtrom S, Rodriguez-Esteban C, Chen L, Tsukui T, Gomer L, Dorward DW, Glinka A, Grinberg A, Huang SP, et al. 2001. Dickkopf1 is required for embryonic head induction and limb morphogenesis in the mouse. Dev Cell 1: 423-434.

Nguyen H, Merrill BJ, Polak L, Nikolova M, Rendl M, Shaver TM, Pasolli HA, Fuchs E. 2009. Tcf3 and Tcf4 are essential for long-term homeostasis of skin epithelia. Nat Genet 41: 1068-1075.

Niehrs C. 2006. Function and biological roles of the Dickkopf family of Wnt modulators. Oncogene 25: 7469-7481.

Rattner A, Hsieh JC, Smallwood PM, Gilbert DI, Copeland NG, Jenkins NA, Nathans J. 1997. A family of secreted proteins contains homology to the cysteine-rich ligand-binding domain of frizzled receptors. Proc Natl Acad Sci 94: 2859-2863.

Schweizer L, Varmus H. 2003. Wnt/Wingless signaling through $\beta$-catenin requires the function of both LRP/Arrow and frizzled classes of receptors. BMC Cell Biol 4: 4. doi: 10.1186/ 1471-2121-4-4.

Shimogori T, VanSant J, Paik E, Grove EA. 2004. Members of the Wnt, Fz, and Frp gene families expressed in postnatal mouse cerebral cortex. I Comp Neurol 473: 496-510.

Shu L, Matveyenko AV, Kerr-Conte J, Cho JH, McIntosh CH, Maedler K. 2009. Decreased TCF7L2 protein levels in type 2 diabetes mellitus correlate with downregulation of GIPand GLP-1 receptors and impaired $\beta$-cell function. Hum Mol Genet 18: 2388-2399.

Tamai K, Semenov M, Kato Y, Spokony R, Liu C, Katsuyama Y, Hess F, Saint-Jeannet JP, He X. 2000. LDL-receptor-related proteins in Wnt signal transduction. Nature 407: 530-535.

Vacik T, Stubbs JL, Lemke G. 2011. A novel mechanism for the transcriptional regulation of Wnt signaling in development. Genes Dev (this issue). doi: 10.1101/gad.17227011.

Veien ES, Rosenthal JS, Kruse-Bend RC, Chien CB, Dorsky RI. 2008. Canonical Wnt signaling is required for the maintenance of dorsal retinal identity. Development 135: 4101-4111.

Wodarz, A. and Nusse, R. 1998. Mechanisms of Wnt signaling in development. Annu Rev Cell Dev Biol 14: 59-88.

Ye F, Chen Y, Hoang T, Montgomery RL, Zhao XH, Bu H, Hu T, Taketo MM, van Es JH, Clevers H, et al. 2009. HDAC1 and HDAC2 regulate oligodendrocyte differentiation by disrupting the $\beta$-catenin-TCF interaction. Nat Neurosci 12: 829-838.

Zhao L, Saitsu H, Sun X, Shiota K, Ishibashi M. 2010. Sonic hedgehog is involved in formation of the ventral optic cup by limiting Bmp4 expression to the dorsal domain. Mech Dev 127: $62-72$. 


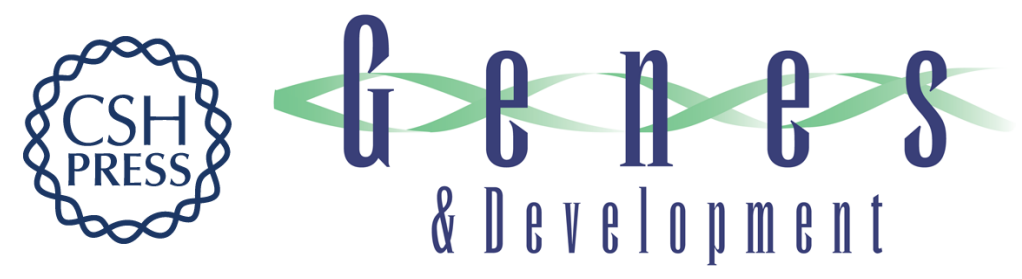

\title{
Wnt signaling meets internal dissent
}

\author{
Elizabeth A. Grove
}

Genes Dev. 2011, 25:

Access the most recent version at doi:10.1101/gad.17594311

\section{Related Content A novel mechanism for the transcriptional regulation of Wnt signaling in development \\ Tomas Vacik, Jennifer L. Stubbs and Greg Lemke \\ Genes Dev. September, 2011 25: 1783-1795 The Repressor Within \\ Annalisa M. VanHook \\ Sci. Signal. September , 2011 4: ec253 \\ References This article cites 32 articles, 13 of which can be accessed free at: \\ http://genesdev.cshlp.org/content/25/17/1759.full.html\#ref-list-1 \\ Articles cited in: \\ http://genesdev.cshlp.org/content/25/17/1759.full.html\#related-urls \\ License \\ Email Alerting \\ Receive free email alerts when new articles cite this article - sign up in the box at the top Service right corner of the article or click here.}

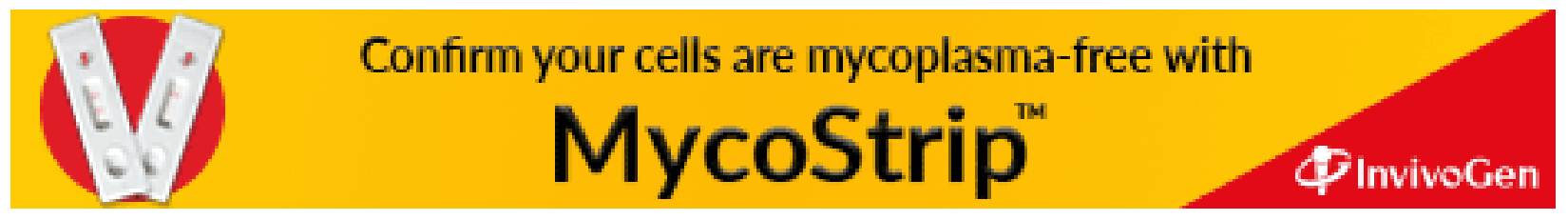

